\title{
Latitudinal and longitudinal clines of phenotypic plasticity in the invasive herb Solidago canadensis in China
}

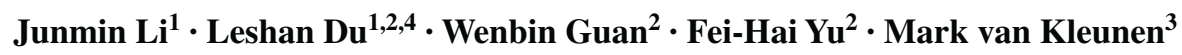

\begin{abstract}
Phenotypic plasticity is thought to be important for plants in variable environments. The climatic variability hypothesis poses that populations at higher latitudes, due to the stronger variation in temperature, there should be more plastic in response to temperature than populations at lower latitudes. Similarly, populations at locations with stronger precipitation fluctuations should be more plastic in response to water availability than populations at locations with less variable precipitation. We sampled seven and nine populations of Solidago canadensis, a North American native that is invasive in China, along a latitudinal (temperature variability) and a longitudinal (precipitation variability) gradient, respectively, in China, and grew them under two temperature treatments and two water-availability treatments, respectively. Among the four traits with significant variation in plasticity among populations in response to temperature, plasticity of leaf length-to-width ratio was
\end{abstract}

Junmin Li

lijm@tzc.edu.cn; lijmtzc@126.com

1 Zhejiang Provincial Key Laboratory of Evolutionary Ecology and Conservation, Taizhou University, Taizhou 318000 , Zhejiang, China

2 School of Nature Conservation, Beijing Forestry University, Beijing 100083, China

3 Department of Biology, University of Konstanz, Universitätsstrasse 10, 78457 Constance, Germany

4 Research Center for Biodiversity, Chinese Research Academy of Environmental Sciences, Beijing 100012, China significantly positively correlated with latitude and temperature seasonality of the populations. In addition, root/shoot ratio and water-use efficiency showed significant variation in plasticity among populations in response to water availability, and plasticities of these two traits were significantly negatively correlated with longitude and positively correlated with precipitation seasonality. The observed geographic clines in plasticity suggest that phenotypic plasticity of $S$. canadensis may have evolved rapidly in regions with different climatic conditions, and this may have contributed to the spread of this invasive species.

Keywords Climatic variability hypothesis · Latitudinal pattern · Longitudinal pattern · Morphological plasticity

\section{Introduction}

Phenotypic plasticity, i.e. the capacity of an organism to express different phenotypes in different environments (Bradshaw 1965), is a widespread phenomenon (Agrawal 2001; Engel et al. 2011), and is likely to play an important role in the adjustment of organisms to changing environments (Agrawal 2001). Compared to narrowly distributed species, widespread ones are expected to be characterized by a higher level of phenotypic plasticity because of larger variation in environmental conditions that they experience (Bradshaw 1965; Pintor et al. 2015). High phenotypic plasticity is also likely to contribute to the spread of invasive alien plants (Baker 1965; Richards et al. 2006; MolinaMontenegro et al. 2013; Keser et al. 2014; but see Davidson et al. 2011). Rapid adaptive evolution along environmental gradients is also commonly observed in invasive plants (Maron et al. 2004; Colautti et al. 2009; Moran and Alexander 2014; Oduor et al. 2016). However, while 
phenotypic plasticity can evolve in response to environmental variability (Scheiner and Lyman 1991; van Kleunen and Fischer 2005), few studies have addressed whether this might have happened during the spread of invasive plants to different latitudes and longitudes (Molina-Montenegro and Naya 2012).

Phenotypic plasticity of widespread species may show clear geographical patterns (Swallow et al. 2005; Overgaard et al. 2011). According to the climatic variability hypothesis (Janzen 1967; Stevens 1989), individuals of a species should show higher phenotypic plasticity in physiological and morphological traits or a broader range of physiological tolerance when climatic variability increases, as happens for temperature with increasing latitude. Empirical evidence for thermal traits mostly supports the prediction of the climatic variability hypothesis, since a positive relationship between thermal tolerance ranges and latitude has been reported for many different taxa (see Brattstrom 1968; Addo-Bediako and Chown 2000; Cruz et al. 2005; Calosi et al. 2008; Deutsch et al. 2008; Naya et al. 2012). However, studies testing relationships between latitude and phenotypic plasticity of traits underlying the thermal tolerance are much scarcer (Addo-Bediako and Chown 2000; Naya et al. 2008, 2012; Molina-Montenegro and Naya 2012). Furthermore, the few existing studies focused mostly on animals (Addo-Bediako and Chown 2000; Maldonado et al. 2011; Naya et al. 2008, 2012). For instance, a positive correlation was reported between plasticity of small intestine length and latitude in rodents (Naya et al. 2008) and between physiological plasticity to temperature and latitude in insects (Addo-Bediako and Chown 2000). On the other hand, Maldonado et al. (2011) did not find a positive relationship between the magnitude of digestive-tract plasticity and latitude in rufous-collared sparrows. To the best of our knowledge, only one study to date has tested such a relationship in plants. Molina-Montenegro and Naya (2012) clearly showed that plasticity in ecophysiological traits to temperature in Taraxacum officinale was positively correlated with latitude. So, while most of the few studies on this topic found positive relationships between plasticity and latitude, more studies, particularly on plants, are required to test how common this relationship is.

Because temperature seasonality increases with latitude, empirical studies testing geographic patterns of phenotypic plasticity focused on the relationship between latitude and phenotypic plasticity in response to temperature (Stevens 1989; Addo-Bediako and Chown 2000; Sunday et al. 2011; Molina-Montenegro and Naya 2012). However, little is known about how precipitation and its seasonality therein, another major climatic axis, affect phenotypic plasticity of plants. In many parts of the world, the amount and variation of precipitation change with longitude. For instance, Shi
(2004) found that in parts of China precipitation increases with decreasing longitude, i.e. there is more precipitation in the east (at larger longitude, near the ocean) and less in the west (at smaller longitude, far away from the ocean). Therefore, if the climatic variability hypothesis holds, then one would expect a relationship between longitude and phenotypic plasticity in response to water availability in China.

To examine how phenotypic plasticities in response to temperature and water availability change with latitude and longitude, respectively, we collected plants of the widespread invasive rhizomatous species Solidago canadensis along a latitudinal and a longitudinal gradient in China. A previous study has suggested that high phenotypic plasticity is an important trait contributing to the invasiveness of S. canadensis (Dong et al. 2006). We grew ramets (asexually produced individuals) of $S$. canadensis under two levels of temperature and two levels of water availability. On these plants we measured physiological traits on the efficiency of photosynthesis [light-use efficiency (LUE), water-use efficiency (WUE)], morphological traits on root allocation (root/shoot ratio) and leaf shape (leaf length-towidth ratio) and performance traits (plant height, biomass). We used these data to address the following questions: (1) Is phenotypic plasticity in response to temperature change positively related to latitude and temperature seasonality of the population of origin? (2) Is phenotypic plasticity in response to water-availability change negatively related to longitude and positively related to precipitation seasonality of the population of origin?

\section{Materials and methods}

\section{Study species}

Solidago canadensis L. (Asteraceae) is a rhizomatous clonal perennial forb native to North America, and is one of the most widespread invasive alien plants in China and in many other countries (Schittko and Wurts 2014). In China, the species was first recorded in the east, in Shanghai, in 1935, and spread from there to the west, north and south of China, where it is now widely distributed (Dong et al. 2006; Lu et al. 2007). Extensive clonal growth of $S$. canadensis leads to dense stands of shoots, which reduces native species diversity (Dong et al. 2006), but without apparent impact on the native soil seed bank (Kundel et al. 2014). Its seeds are small, numerous and wind dispersed, which facilitates long-distance dispersal (Dong et al. 2006). The species occurs between $23^{\circ} \mathrm{N}$ and $39^{\circ} \mathrm{N}$ in China, but it could be based on species distribution modelling that occur up to $50^{\circ} \mathrm{N}$ latitude (Lu et al. 2007). 
(a)

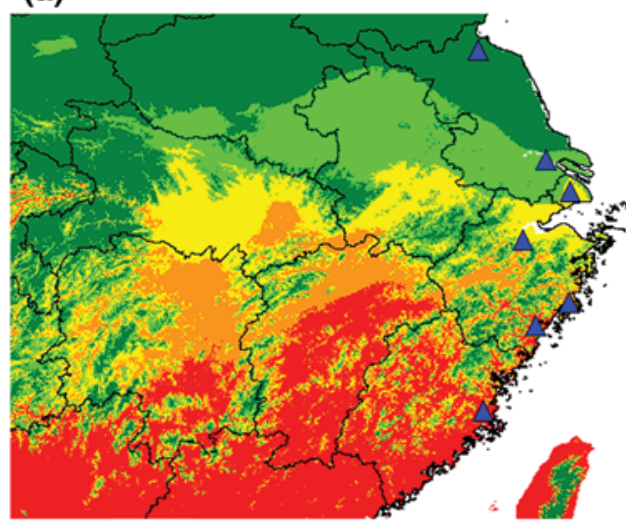

(c)

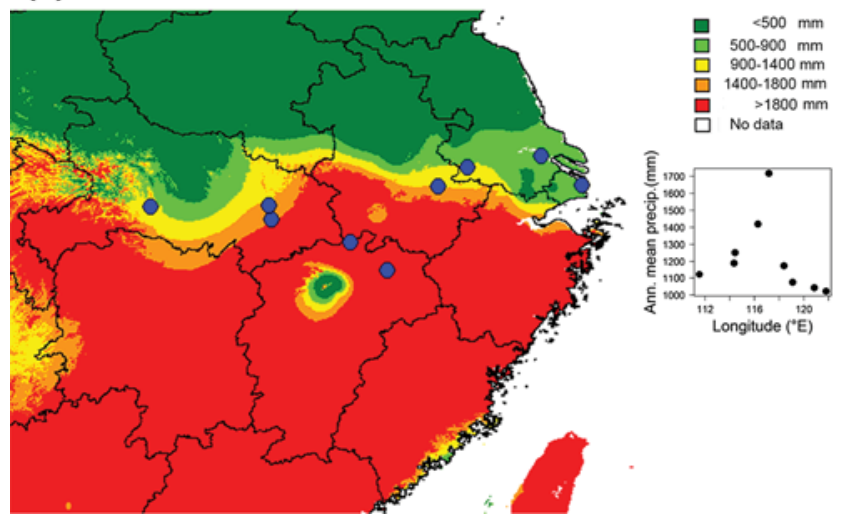

Fig. 1 Sampling locations of Solidago canadensis populations along a latitudinal (north-south) transect across China in relation to a mean annual temperature and $\mathbf{b}$ temperature seasonality gradients and along a longitudinal (east-west) transect of $\mathbf{c}$ mean annual precipitation and

\section{Sampling and propagation of plant material}

In October 2012, rhizomes of S. canadensis were collected from seven populations along a latitudinal transect (Fig. 1a, b, ESM Appendix 1) and nine populations along a longitudinal transect across China (Fig. 1c, d, ESM Appendix 1). Because one population was on both transects, there were 15 populations in total (ESM Appendix 1). The latitude of the populations ranges from $26.0968^{\circ} \mathrm{N}$ to $34.654^{\circ} \mathrm{N}$, and the longitude ranges from $111.532^{\circ} \mathrm{E}$ to $121.804^{\circ} \mathrm{E}$. The two transects span most of the recorded range of $S$. canadensis in China (Lu et al. 2007), and coincide with climatic gradients, especially with regard to variability in temperature and precipitation. This is because in the sampling areas the length of the vegetation period and mean temperature decrease, while temperature seasonality therein increases, with increasing latitude, and mean precipitation and its seasonality therein decrease with increasing longitude (Fig. 1). The sampled populations grew near roads, mostly in ruderal vegetation, which is the typical habitat for this species in China. The geographic coordinates of each (b)

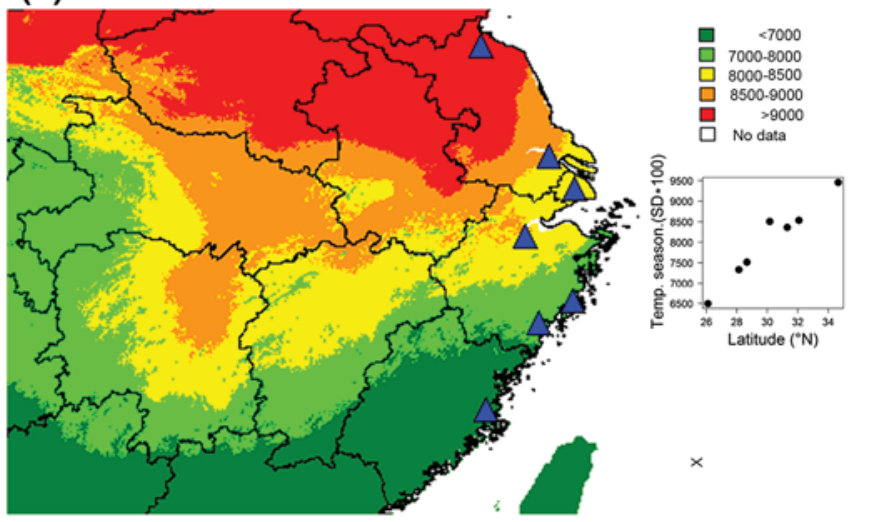

(d)

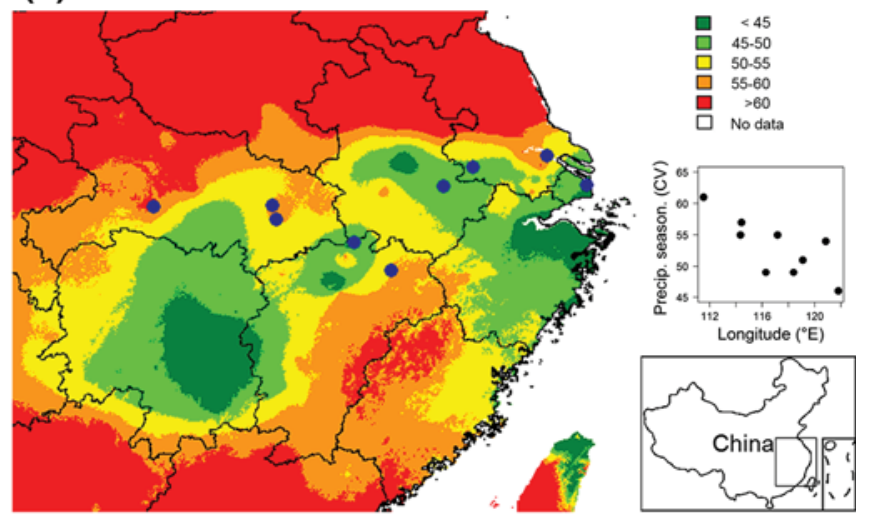

d precipitation seasonality gradients. The annual mean temperature and temperature seasonality vs. latitude, and annual mean precipitation and precipitation seasonality against longitude for all sampling locations are shown as inserts. Color version is available online

population were recorded using an Explorist 600 potable GPS receiver (Magellan Corporation, Santa Clara, California, USA).

Within each population, 12 randomly selected shoots (ramets) with attached rhizomes were dug out. Shoots were removed, and the shoot bases with attached rhizomes were kept moist until replanted. Individual clones of S. canadensis can easily be recognized in the field, because they form dense clusters of stems. Nevertheless, to reduce the chance of sampling the same genet more than once, the distances between collected rhizomes were at least $10 \mathrm{~m}$. A molecular genetic analysis based on five microsatellite loci (see Zuo 2014) confirmed that all collected rhizomes belonged to different genotypes (genets). As $S$. canadensis is known to have different ploidy levels in its native North American range (Croat 1972), and ploidy level might affect plasticity (Levin 2002), we examined the ploidy level of the sampled plants. Therefore, we conducted flow cytometry analysis on fresh young leaf material using an Attune ${ }^{\circledR}$ NxT Acoustic Focusing Cytometer (Grand Island, New York, USA). We found that all sampled plants of $S$. canadensis were 
hexaploid. This indicates that the $S$. canadensis invasion in China happened independently from the one in Europe, where all S. canadensis plants are diploid (van Kleunen and Schmid 2003).

Rhizomes were individually planted in pots (diameter: $30 \mathrm{~cm}$, depth: $30 \mathrm{~cm}$ ), filled with a soil mixture consisting of six parts of yellow clay soil collected from a field in Linhai City, Zhejiang Province, China, three parts of sand and one part of peat soil. The soil mixture had a final $\mathrm{pH}$ of $6.80 \pm 0.10$ (mean $\pm \mathrm{SE}, n=3$ ), an organic matter content of $27.66 \pm 0.69 \mathrm{~g} \mathrm{~kg}^{-1}$, a total nitrogen content of $361.00 \pm 19.05 \mathrm{mg} \mathrm{kg}^{-1}$, an available phosphorus content of $8.00 \pm 0.66 \mathrm{mg} \mathrm{kg}^{-1}$ and an available potassium content of $12.00 \pm 0.58 \mathrm{mg} \mathrm{kg}^{-1}$. To reduce environmental carryover effects, all plant materials used in this study were vegetatively propagated in a greenhouse for at least 4 months.

\section{Temperature experiment}

On May 6, 2013, newly produced ramets with a height of about $15 \mathrm{~cm}$ were cut off from the stock genotypes of $S$. canadensis and individually planted in pots (diameter: $16 \mathrm{~cm}$, depth: $14 \mathrm{~cm}$ ) filled with the same soil mixture as used for the stock population. Pots were randomly allocated to positions on the bench of a walk-in growth chamber $(3.6 \mathrm{~m}$ long $\times 2.7 \mathrm{~m}$ wide $\times 2.2 \mathrm{~m}$ high; Ningbo Jinnan Biological Instrument Co. Ltd., Zhejiang Province, China) in Taizhou University. Inside the chamber the photon flux density was $170 \mu \mathrm{mol} \mathrm{m} \mathrm{m}^{-2} \mathrm{~s}^{-1}$, the photoperiod was set to $14 / 10 \mathrm{~h}$ in light/dark, the humidity was $85 \%$ and the temperature was $22 / 17^{\circ} \mathrm{C}$ in day/night.

On May 20, 2013, we started the temperature experiment using two growth chambers with different temperature regimes. Two ramets from each of 6-9 genets of the seven $S$. canadensis populations (totaling 102 ramets) along the latitudinal transect across China were allocated to two treatments; a control and a high-temperature treatment (one replicate per genotype per treatment). The temperature of the control treatment was set at $22 / 17{ }^{\circ} \mathrm{C}$ in day/night, and the temperature of the high-temperature treatment was set at $32 / 27{ }^{\circ} \mathrm{C}$ in day/night. The experimental temperatures were chosen to cover a large amplitude that is still within the range of temperatures that all source populations can experience in nature (all populations have maximum temperatures of the warmest month over $30{ }^{\circ} \mathrm{C}$ and mean annual temperatures below $22^{\circ} \mathrm{C}$ ).

As we had only one replicate growth chamber per treatment, each temperature treatment had only one true replicate. However, as we were not interested in the temperature effect per se, but in differences in plastic responses among the populations, the pseudo-replication should not invalidate the comparison of plastic responses among populations. The positions of the pots were randomly changed every week within each growth chamber to reduce position effects.

On July 21, 2013, several physiological and morphological traits that are potentially important with regard to responses to temperature and water availability were measured on the $S$. canadensis plants. As physiological traits, we determined LUE and WUE, which are traits that plants frequently adjust in response to environmental change to maximize photosynthesis (Rowlan et al. 2015; Zhou et al. 2015). As morphological traits, we determined root/ shoot ratio, which plants frequently adjust to maximize the uptake of the most limiting resource (Bloom et al. 1985), and leaf length-to-width ratio, which is a measure of leaf shape important for thermoregulation (Nicotra et al. 2011). In addition, we measured plant height and total biomass as performance traits.

In situ measurements of photosynthesis were made on the third fully expanded leaf, counted from the shoot tip, using a portable photosynthesis-measurement system (LI6400 XT, Li-COR Inc., Lincoln, NE, USA) between 9:00 and 11:00 am under a photosynthetically active radiation of $1400 \mu \mathrm{mol} \mathrm{m} \mathrm{m}^{-2} \mathrm{~s}^{-1}$ (i.e. under light saturation) with a leaf temperature of $25^{\circ} \mathrm{C}$, a $\mathrm{CO}_{2}$ concentration of $400 \mathrm{ppm}$ and a relative humidity of $70 \%$. Net photosynthetic rate $\left(P_{\mathrm{n}}\right)$, transpiration rate $(E)$ and intercellular $\mathrm{CO}_{2}$ concentration $\left(C_{\mathrm{i}}\right)$ were measured. Light-use efficiency (LUE) was calculated as $P_{\mathrm{n}} / \mathrm{PAR}$ (Long et al. 1993), and instantaneous water-use efficiency (WUE) was calculated as $P_{\mathrm{n}} / \mathrm{E}$ (Hamid et al. 1990). For every plant, six consecutive measurements were made, and their averages were used in the analyses. After the physiological measurements, we measured the height, length and width of the third leaf of each plant using a flexible ruler with a precision of $0.1 \mathrm{~mm}$. Then, each plant was divided into roots and shoots, dried in an oven at $70{ }^{\circ} \mathrm{C}$ to a constant weight, and weighed. Total biomass and root/shoot ratio $(\mathrm{R} / \mathrm{S})$ were calculated.

\section{Water-availability experiment}

On March 6, 2013, newly produced ramets of about $15 \mathrm{~cm}$ high were cut off from the stock genotypes of $S$. canadensis, and planted individually in pots (diameter: $16 \mathrm{~cm}$, depth: $14 \mathrm{~cm}$ ) filled with the same soil mixture as used for the stock population. Pots were randomly allocated to positions in the greenhouse of Taizhou University in Linhai City, Zhejiang Province, China $\left(121^{\circ} 17^{\prime} \mathrm{E}, 28^{\circ} 87^{\prime} \mathrm{N}\right)$.

On March 20, 2013, a water-availability experiment was started in the greenhouse. Maximum water-holding capacity of the soil mixture used in the experiment was measured gravimetrically (Gotsch et al. 2010) as follows. Soil samples were saturated with water and weighed. Then the samples were dried at $50{ }^{\circ} \mathrm{C}$ for 3 days, and weighed again. Two ramets from each of the 4-9 genets of the nine 
S. canadensis populations (totaling 122 ramets) along the longitudinal transect across China were allocated to two treatments, a well-watered control and a drought treatment (one replicate per genotype per population per treatment). So, we used the same genetic material in each treatment. In the control treatment, the soil-available moisture was maintained at 75-80\% of the maximum water-holding capacity of the substrate. In the drought treatment, it was maintained at 20-25\%. Although we do not have data on the soil-available moisture in the populations of origin, the chosen amplitude is likely to be within the range of values that plants experience in natural populations. Water content of the soil was daily measured gravimetrically, and water was added as necessary to maintain the treatment differences. The positions of the pots were randomly changed every week to reduce position effects. From May 21 to 27, 2013, the same physiological, morphological and performance-related traits were measured as in the temperature experiment described above.

\section{Climate data}

For each population, we extracted data on climatic variables from the WorldClim data base (http://www.worldclim.org/current) using the DIVA-GIS software (version 7.2.1.1, http://www.diva-gis.org). The bioclimatic variables were calculated from monthly temperature and rainfall data in the period 1950-2000, interpolated at 30-s resolution (c. $1 \mathrm{~km}^{2}$ resolution, see http://www.worldclim.org/ and Hijmans et al. 2005). Although these interpolated climate data might deviate from the true values, they are the best data available. Bioclimatic variables used in our study are annual mean temperature $\left({ }^{\circ} \mathrm{C}\right)$ and temperature seasonality (standard deviation $\times 100$ ) for the populations in the temperature experiment, and annual mean precipitation ( $\mathrm{mm}$ ) and precipitation seasonality (coefficient of variation) for the populations in the water-availability experiment.

\section{Statistical analyses}

To test whether traits related to physiology (LUE, WUE), morphology (leaf length-to-width ratio, root/shoot ratio) and performance (plant height, biomass) were significantly affected by the treatments and varied among populations, we used two-way ANOVAs. In these models, treatment (either water availability or temperature) was included as a fixed factor. Because populations were randomly chosen along the geographic/climatic gradients, population and its interaction with the treatment were included as random factors.

To test whether plasticity in the physiological, morphological and performance traits is correlated with latitude and longitude and variation in climatic variables of the populations, we calculated for each population an average phenotypic plasticity index (PPI) of each trait based on the PPI values of the individual genotypes. The PPI was calculated as: $(\max (x 0, x i)-\min (x 0, x i)) / \max (x 0, x i)$, where $\mathrm{x} 0$ and $\mathrm{xi}$ stand for the mean values of the control and the drought or high-temperature treatments, respectively. $\operatorname{Max}(\mathrm{x} 0, \mathrm{xi})$ is the larger value of $\mathrm{x} 0$ and $\mathrm{xi}$, and $\min (\mathrm{x} 0$, xi) the smaller value of $\mathrm{x} 0$ and $\mathrm{xi}$ (Cheplick 1995; Valladares et al. 2006). PPI per population was calculated as the mean of the PPI values of the genotypes in each population. Although PPI quantifies the magnitude of plasticity very well, it does not consider the direction of the plastic response. Therefore, we also calculated a directional plasticity index as (x0-xi)/x0 (Valladares et al. 2006). However, as the results were very similar (compare Tables 1, 2 with ESM Appendices 2 and 3), we only represent the results of PPI in the main text, as the climatic variability hypothesis makes no clear predictions regarding the direction of plasticity. The relationships of phenotypic plasticity (PPI) with latitude, longitude and climate data were evaluated using Pearson's correlation tests (see also Molina-Montenegro and Naya 2012). As tests for such correlations assume that populations differ in plasticity, we only did these tests for traits with significant environment $\times$ population interactions in the two-way ANOVAs. All statistical analyses were conducted using SPSS 16.0 software.

\section{Results}

\section{Correlations of temperature induced plasticity with latitude, mean temperature and its variability}

Averaged across all populations in the temperature experiment, plants of $S$. canadensis significantly decreased their WUE and root/shoot ratio, and increased their LUE in response to increased temperature. For plant height, leaf length-to-width ratio and biomass, the average values of the plants were not significantly different between the control and high-temperature treatment (Table 1). Nevertheless, for all of the latter traits, as well as for LUE, there was significant variation in plasticity among populations (significant temperature $\times$ population interactions in Table 1 ).

Among the four traits with significant variation among populations in plasticity to temperature, phenotypic plasticity of leaf length-to-width ratio was higher in the northern than in the southern populations, and consequently significantly positively related with latitude (Fig. 2a; Table 1). This coincided with a significant positive correlation of plasticity in leaf length-to-width ratio with temperature seasonality (Fig. 2c; Table 1), and a significant negative correlation with annual mean temperature (Fig. 2b; Table 1). 
Table 1 Physiological, morphological and performance traits of Solidago canadensis in the control and high-temperature treatment and phenotypic plasticity index (PPI) of each of these traits

\begin{tabular}{|c|c|c|c|c|c|c|c|c|}
\hline \multirow[t]{2}{*}{ Trait } & \multicolumn{4}{|c|}{ Temperature effect } & \multicolumn{4}{|c|}{ Phenotypic plasticity index } \\
\hline & $\begin{array}{l}\text { Control } \\
(\text { mean } \pm \text { SE })\end{array}$ & $\begin{array}{l}\text { High temp. } \\
(\text { mean } \pm \text { SE) }\end{array}$ & $\begin{array}{l}\text { Temp. } \\
F_{1,6}\end{array}$ & $\begin{array}{l}\text { Temp. } \times \text { pop. } \\
F_{6,88}\end{array}$ & Mean \pm SE & $r$ (latitude) & $\begin{array}{l}r \text { (annual mean } \\
\text { temperature) }\end{array}$ & $\begin{array}{l}r \text { (temperature } \\
\text { seasonality) }\end{array}$ \\
\hline Plant height $(\mathrm{cm})$ & $43.83 \pm 4.29$ & $56.93 \pm 3.95$ & 3.74 & $28.56 * * *$ & $0.28 \pm 0.07$ & -0.30 & -0.04 & -0.30 \\
\hline $\begin{array}{l}\text { Leaf length-to- } \\
\text { width ratio }\end{array}$ & $5.15 \pm 0.18$ & $4.89 \pm 0.25$ & 0.89 & $3.11 * *$ & $0.17 \pm 0.02$ & $0.82 *$ & $-0.73^{*}$ & $0.77 *$ \\
\hline Biomass (g) & $4.68 \pm 0.40$ & $4.70 \pm 0.57$ & $<0.01$ & $7.61 * * *$ & $0.35 \pm 0.03$ & 0.50 & $-0.78^{*}$ & 0.46 \\
\hline Root/shoot ratio & $0.50 \pm 0.03$ & $0.22 \pm 0.01$ & $138.16^{* * *}$ & 1.02 & $0.53 \pm 0.02$ & - & - & - \\
\hline $\begin{array}{l}\text { Light-use } \\
\text { efficiency } \\
\left(\mu \mathrm{mol} \mathrm{mmol}^{-1}\right)\end{array}$ & $3.13 \pm 0.09$ & $4.80 \pm 0.36$ & $17.205^{* *}$ & $2.66^{*}$ & $0.36 \pm 0.04$ & -0.65 & 0.42 & -0.55 \\
\hline $\begin{array}{l}\text { Water-use } \\
\text { efficiency } \\
\left(\mu \mathrm{mol} \mathrm{mmol}^{-1}\right)\end{array}$ & $4.37 \pm 0.14$ & $1.59 \pm 0.11$ & $320.15 * * *$ & 0.26 & $0.55 \pm 0.03$ & - & - & - \\
\hline
\end{tabular}

$F$ values and their significances for temperature effect and temperature $\times$ population interaction from a two-way ANOVA are given. Pearson correlation coefficients $(r)$ between mean PPI values and latitude, annual mean temperature and temperature seasonality of populations $(n=7)$ are also given for variables where the temperature $\times$ population interaction is significant

$* P<0.05, * * P<0.01, * * * P<0.001$

Table 2 Physiological, morphological and performance traits of Solidago canadensis in the control and drought treatment and phenotypic plasticity index (PPI) of each of these traits

\begin{tabular}{|c|c|c|c|c|c|c|c|c|}
\hline \multirow[t]{2}{*}{ Trait } & \multicolumn{4}{|l|}{ Drought effect } & \multicolumn{4}{|c|}{ Phenotypic plasticity index } \\
\hline & $\begin{array}{l}\text { Control } \\
(\text { mean } \pm \mathrm{SE})\end{array}$ & $\begin{array}{l}\text { Drought } \\
(\text { mean } \pm \mathrm{SE})\end{array}$ & $\begin{array}{l}\text { Drought } \\
F_{1,8}\end{array}$ & $\begin{array}{l}\text { Drought } \times \text { pop. } \\
F_{8,104}\end{array}$ & Mean \pm SE & $r$ (longitude) & $\begin{array}{l}r \text { (annual mean } \\
\text { precipitation) }\end{array}$ & $\begin{array}{l}r \text { (precipitation } \\
\text { seasonality) }\end{array}$ \\
\hline Plant height (cm) & $58.55 \pm 2.05$ & $18.70 \pm 1.60$ & $260.38 * * *$ & 1.63 & $0.67 \pm 0.03$ & - & - & - \\
\hline $\begin{array}{l}\text { Leaf length-to- } \\
\text { width ratio }\end{array}$ & $5.93 \pm 0.28$ & $5.66 \pm 0.23$ & 0.92 & 1.63 & $0.17 \pm 0.02$ & - & - & - \\
\hline Biomass (g) & $3.95 \pm 0.22$ & $1.49 \pm 0.18$ & $204.35^{* * *}$ & 0.37 & $0.61 \pm 0.04$ & - & - & - \\
\hline Root/shoot ratio & $0.38 \pm 0.02$ & $0.87 \pm 0.08$ & $36.60 * * *$ & $2.39 *$ & $0.49 \pm 0.04$ & $-0.74 *$ & -0.10 & $0.72 *$ \\
\hline $\begin{array}{l}\text { Light-use } \\
\text { efficiency } \\
\left(\mu \mathrm{mol} \mathrm{mmol}^{-1}\right)\end{array}$ & $7.39 \pm 0.23$ & $3.25 \pm 0.15$ & $176.88 * * *$ & 1.73 & $0.55 \pm 0.03$ & - & - & - \\
\hline $\begin{array}{l}\text { Water-use } \\
\text { efficiency } \\
\left(\mu \mathrm{mol} \mathrm{mmol}^{-1}\right)\end{array}$ & $1.53 \pm 0.04$ & $12.94 \pm 2.52$ & $29.17 * *$ & $5.55^{* * *}$ & $0.81 \pm 0.02$ & $-0.71 *$ & -0.32 & $0.83^{*}$ \\
\hline
\end{tabular}

$F$ values and their significances for drought effect and drought $\times$ population interaction from a two-way ANOVA are given. Pearson correlation coefficients $(r)$ between mean PPI values and latitude, annual mean precipitation and precipitation seasonality of populations $(n=9)$ are also given for variables when the drought $\times$ population interaction is significant

$* P<0.05, * * P<0.01, * * * P<0.001$

\section{Correlations of water-availability induced plasticity with longitude, mean precipitation and its variability}

Averaged across all populations in the water-availability experiment, plants of $S$. canadensis significantly decreased their height, biomass and LUE, and increased their root/ shoot ratio and WUE in response to drought (Table 2). Leaf length-to-width ratio was not significantly affected by the drought treatment (Table 2). For root/shoot ratio and WUE the degree of plasticity varied significantly among populations (significant drought $\times$ population interactions in Table 2).

For both traits with significant variation among populations in plasticity to water availability, i.e. root/shoot ratio and WUE, their plasticities were higher in the western populations than in the eastern populations, and consequently 

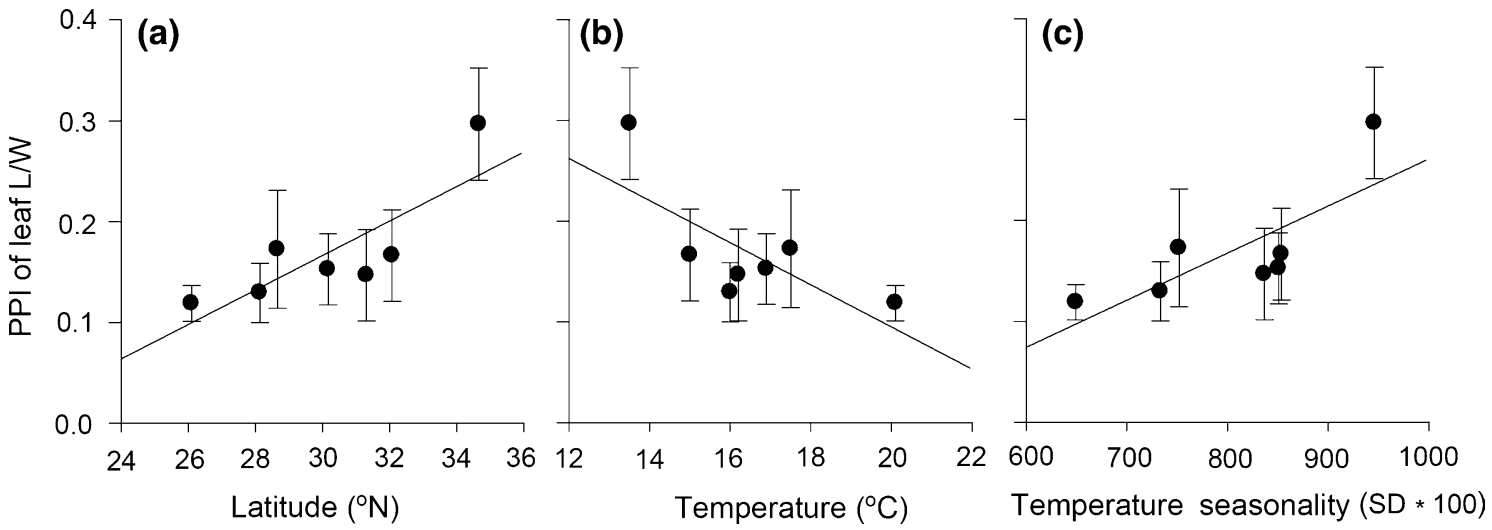

Fig. 2 Relationships of mean ( \pm SE) phenotypic plasticity index (PPI) of leaf length-to-width ratio (L/W) of Solidago canadensis populations in response to changing temperature with a latitude, $\mathbf{b}$ annual mean temperature and $\mathbf{c}$ temperature seasonality of the populations of origin
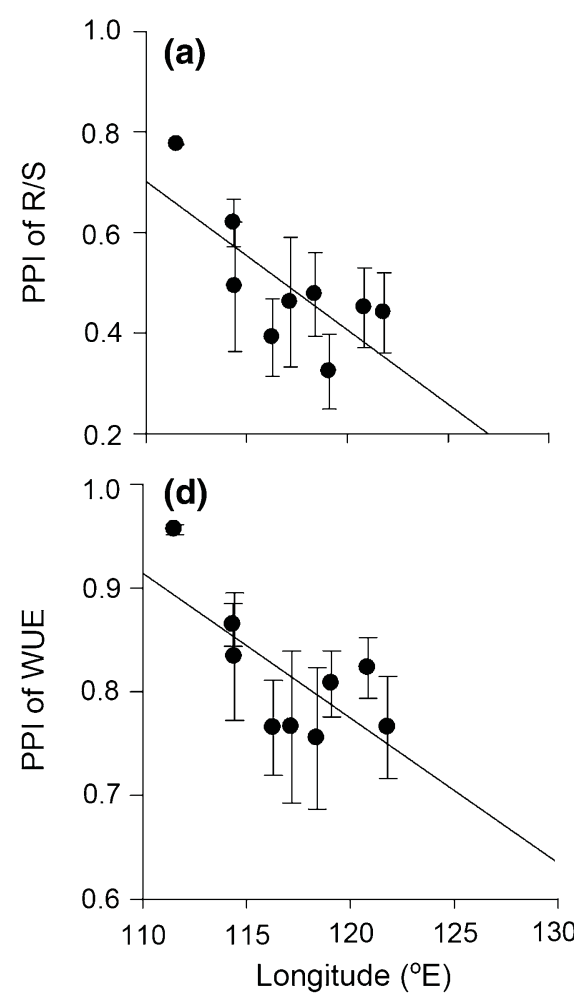

(b)

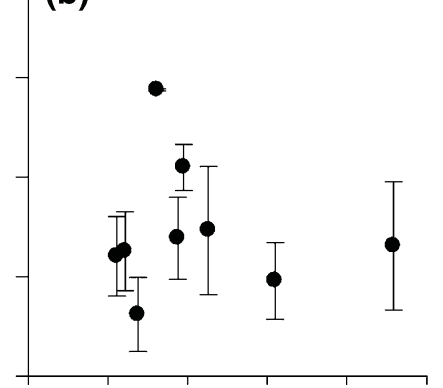

(e)

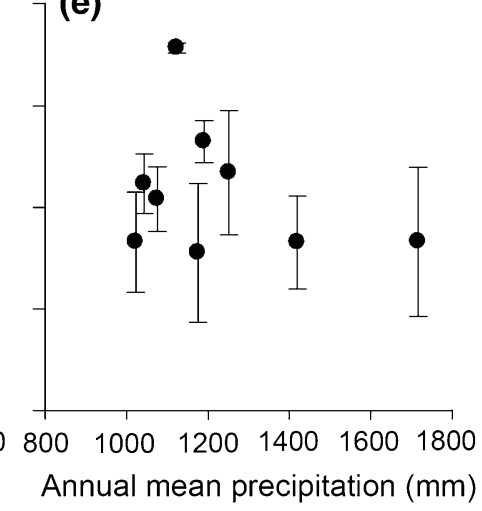

(c)

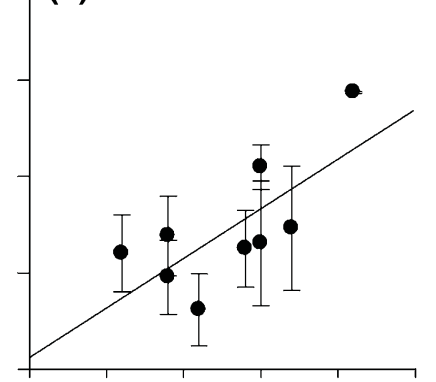

(f)

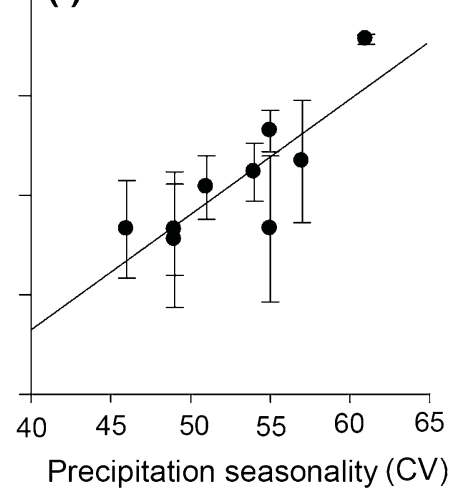

Fig. 3 Relationships of mean $( \pm$ SE) phenotypic plasticity index (PPI) of a-c root/shoot ratio (R/S) and $\mathbf{d}-\mathbf{f}$ water utilization efficiency (WUE) of Solidago canadensis populations in response to drought

significantly negatively related with longitude (Fig. 3a, d; Table 2). This coincided with significant positive correlations of plasticities of both traits with precipitation seasonality, but not with mean annual precipitation (Fig. 3b, c, e, f; Table 2). with a, $\mathbf{d}$ longitude, $\mathbf{b}, \mathbf{e}$ mean annual precipitation and $\mathbf{c}, \mathbf{f}$ precipitation seasonality of the population of origin

\section{Discussion}

Plants of S. canadensis responded to temperature and water availability with plastic changes in physiological, morphological and performance traits. Populations also 
varied in the degree and/or direction of many of their plastic responses. For several of the measured traits, variation in the degree of plasticity was related to the latitude and longitude of origin, in such a way that plasticity increased with seasonality in temperature and seasonality in precipitation, respectively. Our results thus provide support for the climatic variability hypothesis (Janzen 1967; Stevens 1989).

\section{Latitudinal pattern of phenotypic plasticity to temperature in $S$. canadensis}

For four of the six traits measured in our study, there was significant variation in plasticity in response to temperature among the seven populations. This suggest that evolutionary change has resulted in genetic differentiation in plasticity in response to temperature among populations. However, there are also several alternative possibilities than evolutionary change. First, it could be that different strains of $S$. canadensis have been introduced to different parts of China. Second, it could be that environmental maternal carry-over effects (e.g. Galloway 2005) or epigenetic differences are responsible for the observed among-population differentiation (Bossdorf et al. 2008). Future common garden experiments using seed material instead of rhizome pieces and studies using molecular genetic and epigenetic markers might reveal which of these scenarios is most likely.

For leaf length-to-width ratio, the magnitude of plasticity increased with the latitude of origin, decreased with annual mean temperature and increased with temperature seasonality. Other studies on invasive plants have frequently revealed latitudinal clines with regard to mean trait values (van Kleunen and Fischer 2008; Colautti et al. 2009), and that at least some of these latitudinal clines may reflect local adaptation (Colautti and Barrett 2013). Although our data do not allow to separate the effects of annual mean temperature and temperature seasonality in the populations of origin, the correlation between plasticity and temperature seasonality is in line with the predictions of the climatic variability hypothesis (Janzen 1967; Stevens 1989). This finding thus suggests that $S$. canadensis may have rapidly adapted after its introduction to Shanghai in 1935 and during its subsequent spread to the north and south of China by changing the plasticity of at least one of its traits to temperature. Similarly, Molina-Montenegro and Naya (2012) demonstrated that phenotypic plasticity of photosynthesis, foliar angle, number of flowers, WUE, biomass and seed-output of the invasive plant $T$. officinale in response to temperature increased with increasing latitude. Although the climate variability hypothesis was developed for widespread native species, and has been tested for native animals, we are not aware of any study that has tested it for a native plant species.
Latitude is correlated with several climatic and ecological factors that could affect the evolution of mean trait values and of phenotypic plasticity (e.g. Neuffer and Hurka 1986; Weber and Schmid 1998; Molina-Montenegro and Naya 2012). Indeed many studies have revealed evidence for genetic latitudinal clines in the native as well as nonnative ranges of species (Colautti et al. 2009). We are not aware of any studies that tested for genetic latitudinal clines in the native range of $S$. canadensis. However, Weber and Schmid (1998) tested in a common-garden experiment for such clines in the non-native range of $S$. altissima, which is now considered to be $S$. canadensis, in Europe. They found that plants of this species from higher latitudes flowered earlier and at a smaller size than the ones from lower latitudes, which suggests that rapid evolution within the non-native ranges of invasive species is possible. However, to the best of our knowledge, no previous study had yet tested for latitudinal clines in phenotypic plasticity of $S$. canadensis.

\section{Longitudinal pattern of phenotypic plasticity to water availability in $S$. canadensis}

Of the studies that tested for geographical clines in plasticity, the majority focused on either latitudinal or altitudinal clines because of their clear associations with the mean and variation in temperature (Moran and Alexander 2014). However, climatic variables and variation therein can also change along longitudinal clines (Shi 2004). Indeed, plants from western populations of $S$. canadensis in China showed significantly stronger plasticity in root/shoot ratio and water use efficiency in response to water availability than plants from more eastern populations. Our study is thus, to the best of our knowledge, the first one to report significant longitudinal clines in phenotypic plasticity.

In parts of China, precipitation and variation therein are significantly affected by the distance from the ocean in the east (Shi 2004). Along our longitudinal transect, annual mean precipitation was highest at intermediate longitudes, while precipitation seasonality clearly decreased with longitude (Fig. 1c, d). Although plasticity in root/shoot ratio and WUE were correlated with longitude, the magnitude of plasticity was not associated with annual mean precipitation. However, plasticity in both traits was significantly correlated with precipitation seasonality. These findings indicate that the longitudinal clines in plasticity of $S$. canadensis in China are driven by seasonality in precipitation rather than by the mean precipitation. These findings thus strongly support the climatic variability hypothesis.

\section{Implications for invasiveness and conclusions}

High phenotypic plasticity has frequently been invoked to be a mechanism that promotes a species' invasiveness 
(Baker 1965; Richards et al. 2006). Meta-analyses have not revealed consistent patterns in this regard (Davidson et al. 2011), but this could be because most studies have compared invasive species to native instead of to non-invasive alien species (van Kleunen et al. 2010). Here, we showed that within the non-native range of an invasive species, there can also be among-population variation in phenotypic plasticity of physiological and morphological traits. This shows that plasticity is not a static characteristic of a species, but is variable and may also change.

Since its introduction in 1935 to Shanghai, along the eastern coast of China, S. canadensis has spread to large parts of China. Its currently expanding range margins are in the west and north of China, exactly where plasticity in the measured traits is highest. Other studies on geographical patterns in plasticity have hypothesized that plasticity should be highest in peripheral populations because environmental variation is likely to be high there (Volis et al. 1998). Others, however, argued that due to founder effects and limited genetic variation, plasticity should be lower at the margins than in the center of a species' range (Mägi et al. 2011). While the latter is not supported by our findings, the former is. We could not explicitly test whether the observed plastic responses are adaptive (i.e. increase reproductive fitness) in this study. However, if we assume they are, the higher plasticity at this species' western and norther range margins is likely to have helped this species to rapidly invade China, and is likely to further speed up its expansion.

Acknowledgments We thank Jianqing Ding and Zhengsheng He for their kind help in collecting plants. This work was financially supported by the National Natural Science Foundation of China (No. 31270461), the National Key Research and Development Program (2016YFC1201100) and the Qianjiang Talents Project of Zhejiang Province (type D), China (No. QJD1302021). MvK acknowledges financial support from the DFG SPP1819 Rapid Evolutionary Adaptation (KL 1866/10-1).

\section{Compliance with ethical standards}

Conflict of interest The authors declare that they have no conflict of interest.

Author contribution statement JML, WBG, FHY and MK conceived and designed the experiments. LSD performed the experiments. JML, FHY, MK analyzed the data. JML, FHY, MK wrote the manuscript.

\section{References}

Addo-Bediako A, Chown SL, Gaston KJ (2000) Thermal tolerance, climatic variability and latitude. Proc R Soc Lond B 267:739745. doi:10.1098/rspb.2000.1065

Agrawal AA (2001) Phenotypic plasticity in the interactions and evolution of species. Science 294:321-326. doi:10.1126/ science. 1060701
Baker HG (1965) Characteristics and modes of origin of weeds. In: Baker HG, Stebbins GL (eds) The genetics of colonizing species. Academic, New York, pp 147-172

Bloom AJ, Chapin FS III, Mooney HA (1985) Resource limitation in plants: an economic analogy. Ann Rev Ecol System 16:363-392. doi:10.1146/annurev.es.16.110185.002051

Bossdorf O, Richards CL, Pigliucci M (2008) Epigenetic for ecologists. Ecol Lett 11:106-115. doi:10.1111/j.1461-0248.2007.01130.x

Bradshaw AD (1965) Evolutionary significance of phenotypic plasticity in plants. Adv Genet 13:115-155. doi:10.2307/1311135

Brattstrom BH (1968) Thermal acclimation in anuran amphibians as a function of latitude and altitude. Comp Biochem Physiol 24:93111. doi:10.1016/0010-406X(68)90961-4

Calosi P, Bilton DT, Spicer JI (2008) Thermal tolerance, acclimatory capacity and vulnerability to global climate change. Biol Lett 4:99-102. doi:10.1098/rsbl.2007.0408

Cheplick GP (1995) Genotypic variation and plasticity of clonal growth in relation to nutrient availability in Amphibromus scabrivalvis. J Ecol 83:459-468. doi:10.2307/2261599

Colautti RI, Barrett SCH (2013) Rapid adaptation to climate facilitates range expansion of an invasive plant. Science 342:364-366. doi:10.1126/science. 1242121

Colautti RI, Maron JL, Barrett SCH (2009) Common garden comparisons of native and introduced plant populations: latitudinal clines can obscure evolutionary inferences. Evol Appl 2:187-199. doi:10.1111/j.1752-4571.2008.00053.x

Croat T (1972) Solidago canadensis complex of the Great Plains. Brittonia 24:317-326. doi:10.2307/2805669

Cruz FB, Fitzgerald LA, Espinoza RE, Schulter JA II (2005) The importance of phylogenetic scale in tests of Bergmann's and Rapoport's rules: lessons from a clade of South American lizards. J Evol Biol 18:1559-1574. doi:10.1111/j.1420-9101.2005.00936.x

Davidson AM, Jennions M, Nicotra AB (2011) Do invasive species show higher phenotypic plasticity than native species and if so, is it adaptive? A meta-analysis. Ecol Lett 14:419-431. doi:10.1111/j.1461-0248.2011.01596.x

Deutsch CA, Tewksbury JJ, Huey RB, Sheldon KS, Ghalambor CK, Haak DC, Martin PR (2008) Impacts of climate warming on terrestrial ectotherms across latitude. Proc Natl Acad Sci 105:6668-6672

Dong M, Lu JZ, Zhang WJ, Chen JK, Li B (2006) Canada goldernrod (Solidago canadensis): an invasive alien weed rapidly spreading in China. Acta Phytotax Sinica 44:72-85

Engel K, Tollrian R, Jeschke JM (2011) Integrating biological invasions, climate change and phenotypic plasticity. Comm Integ Biol 4:247-250. doi:10.4161/cib.4.3.14885

Galloway L (2005) Maternal effects provide phenotypic adaptation to local environmental conditions. New Phyt 166:93-100. doi:10.1111/j.1469-8137.2004.01314.x

Gotsch SG, Powers JS, Lerdau MT (2010) Leaf traits and water relations of 12 evergreen species in Costa Rican wet and dry forests: patterns of intra-specific variation across forests and seasons. Plant Ecol 211:133-146. doi:10.1007/s11258-010-9779-9

Hamid MA, Agata W, Kawamitsu Y (1990) Photosynthesis, transpiration and water use efficiency in four cultivars of mungbean. Photosynthetica 24:96-101. doi:10.1023/A:1015660213811

Hijmans RJ, Cameron SE, Parra JL, Jones PG, Jarvis A (2005) Very high resolution interpolated climate surfaces for global land areas. Int J Climatol 25:1965-1978. doi:10.1002/ joc. 1276

Janzen DH (1967) Why mountain passes are higher in the tropics. Am Nat 101:233-249

Keser LH, Dawson W, Song YB, Yu FH, Fischer M, Dong M, van Kleunen M (2014) Invasive clonal plant species have a greater 
root-foraging plasticity than non-invasive ones. Oecologia 174:1055-1064. doi:10.1007/s00442-013-2829-y

Kundel D, van Kleunen M, Dawson W (2014) Invasion by Solidago species has limited impacts on soil seedbank communities. Basic Appl Ecol 15:573-580. doi:10.1016/j.baae.2014.08.009

Levin D (2002) The Role of Chromosomal Change in Plant Evolution. Oxford University Press, New York

Long SP, Baker NR, Rains CA (1993) Analyzing the responses of photosynthetic $\mathrm{CO}_{2}$ assimilation to long-term elevation of atmospheric $\mathrm{CO}_{2}$ concentration. Vegetation 104:33-45. doi:10.1007/ BF00048143

Lu JZ, Weng ES, Wu XW, Weber E, Zhao B, Li B (2007) Potential distribution of Solidago canadensis in China. Acta Phytotax Sin 45:670-674. doi:10.1360/aps06200

Mägi M, Semchenko M, Kalamees R, Zobel K (2011) Limited phenotypic plasticity in range-edge populations: a comparison of co-occurring populations of two Agrimonia species with different geographical distributions. Plant Biol 13:177-184. doi:10.1111/j.1438-8677.2010.00342.x

Maldonado K, Bozinovic F, Rojas JM, Sabat P (2011) Within-species digestive tract flexibility in Rufous-collared sparrows and the climatic variability hypothesis. Physiol Biochem Zool 84:377-384. doi:10.1086/660970

Maron JL, Vilà M, Bommarco R, Elmendorf S, Beardsley P (2004) Rapid evolution of an invasive plant. Ecol Monogr 74:261-280. doi:10.1890/03-4027

Molina-Montenegro MA, Naya DE (2012) Latitudinal patterns in phenotypic plasticity and fitness related traits: assessing the climatic variability hypothesis $(\mathrm{CVH})$ with an invasive plant species. PLoS One 7:e47620. doi:10.1371/journal.pone.0047620

Molina-Montenegro MA, Palma-Rojas C, Alcayaga-Olivares Y, Oses R, Corcuera LJ, Cavieres LA (2013) Ecophysiological plasticity and local differentiation help explain the invasion success of Taraxacum officinale (dandelion) in South America. Ecography 36:718-730. doi:10.1111/j.1600-0587.2012.07758.x

Moran EV, Alexander JM (2014) Evolutionary responses to global change: lessons from invasive species. Ecol Lett 17:637-649. doi:10.1111/ele.12262

Naya DE, Bozinovic F, Karasov WH (2008) Latitudinal trends in digestive flexibility: testing the climatic variability hypothesis with data on the intestinal length of rodents. Am Nat 172:122134. doi:10.1086/590957

Naya DE, Spangenberg L, Naya H, Bozinovic F (2012) Latitudinal patterns in rodent metabolic flexibility. Am Nat 179:172-179. doi:10.1086/665646

Neuffer B, Hurka H (1986) Variation of development time until flowering in natural populations of Capsella bursa-pastoris (Cruciferae). Plant System Evol 152:277-296. doi:10.1007/ BF00989433

Nicotra AB, Leigh A, Boyce CK, Jones CS, Niklas KJ, Royer DL, Tsukaya H (2011) The evolution and functional significance of leaf shape in the angiosperms. Funct Plant Biol 38:535-552. doi:10.1071/FP11057

Oduor AMO, Leimu R, van Kleunen M (2016) Invasive plant species are locally adapted just as frequently and at least as strongly as native plant species. J Ecol 104:957-968. doi:10.1111/1365-2745.12578

Overgaard J, Kristensen TN, Mitchell KA, Hoffmann AA (2011) Thermal tolerance in widespread and tropical drosophila species: does phenotypic plasticity increase with latitude? Am Nat 178:S80 S96. doi:10.1086/661780

Pintor AFV, Schwarzkopf L, Krockenberger AK (2015) Rapoport's rule: do climatic variability gradients shape range extent? Ecol Monog 85:643-659. doi:10.1890/14-1510.1
Richards CL, Bossdorf O, Muth NZ, Gurevitch J, Pigliucci M (2006) Jack of all trades, master of some? On the role of phenotypic in plant invasions. Ecol Lett 9:981-993. doi:10.1111/j.1461-0248.2006.00950.x

Rowlan L, Lobo-do-vale RL, Christoffersen BO, Melem EA, Kruijt B, Vasconcelos SS, Domingues T, Binks OJ, Oliveira AAR, Metcalfe D, Da Costa ACL, Mencuccini M, Meir P (2015) After more than a decade of soil moisture deficit, tropical rainforest trees maintain photosynthetic capacity, despite increased leaf respiration. Global Change Biol 21:4662-4672. doi:10.1111/ gcb. 13035

Scheiner SM, Lyman RF (1991) The genetics of phenotypic plasticity. II. Response to selection. J Evol Biol 4:23-50. doi:10.1046/j.1420-9101.1991.4010023.x

Schittko C, Wurts S (2014) Above- and belowground effects of plant-soil feedback from exotic Solidago canadensis on native Tanacetum vulgare. Biol Invas 16:1465-1479. doi:10.1007/ s10530-013-0584-y

Shi XY (2004) Regional climate meridional and zonal feature in China. Msc dissertation, Chinese Academy of Meteorological Science, Beijing, China

Stevens GC (1989) The latitudinal gradient in geographical range: how so many species coexist in the tropics. Am Nat 133:240 256. doi:10.1086/284913

Sunday JM, Bates AE, Dulvy NK (2011) Global analysis of thermal tolerance and latitude in ectotherms. Proc R Soc Lond B 278:1823-1830. doi:10.1098/rspb.2010.1295

Swallow JG, Rhodes JS, Garland T (2005) Phenotypic and evolutionary plasticity of organ masses in response to voluntary exercise in house mice. Integ Comp Biol 45:426-437. doi:10.1093/ icb/45.3.426

Valladares F, Sanchez-Gomez D, Zavala MA (2006) Quantitative estimation of phenotypic plasticity: bridging the gap between the evolutionary concept and its ecological applications. J Ecol 94:1103-1116. doi:10.1111/j.1365-2745.2006.01176.x

van Kleunen M, Fischer M (2005) Constraints on the evolution of adaptive phenotypic plasticity in plants. New Phyt 166:49-60. doi:10.1111/j.1469-8137.2004.01296.x

van Kleunen M, Fischer M (2008) Adaptive rather than non-adaptive evolution of Mimulus guttatus in its invasive range. Basic Appl Ecol 9:213-223. doi:10.1016/j.baae.2007.03.006

van Kleunen M, Schmid B (2003) No evidence for an evolutionary increased competitive ability in an invasive plant. Ecology 84:2816-2823. doi:10.1890/02-0494

van Kleunen M, Dawson W, Schlaepfer DR, Jeschke JM, Fischer M (2010) Are invaders different? A conceptual framework of comparative approaches for assessing determinants of invasiveness. Ecol Lett 13:947-958. doi:10.1111/j.1461-0248.2010.01503.x

Volis S, Mendlinger S, Olsvig-Whittaker L, Safriel UN, Orlovsky N (1998) Phenotypic variation and stress resistance in core and peripheral populations of Hordeum spontaneum. Biodivers Conserv 7:799-813. doi:10.1023/A:844504010

Weber E, Schmid B (1998) Latitudinal population differentiation in two species of Solidago (Asteraceae) introduced into Europe. Am J Bot 85:1110-1121. doi:10.1046/j.1420-9101.2002.00457.x

Zhou L, Wang SQ, Chi YG, Li QK, Huang K, Yu QZ (2015) Responses of photosynthetic parameters to drought in subtropical forest ecosystem of China. Sci Rep 5:18254-18264. doi:10.1038/srep18254

Zuo W (2014) Genetic diversity and molecular phylogeograpy of invasive Solidago canadensis L. Master thesis, School of Life Science, Shanghai Normal University, Shanghai, China 